\title{
Evaluation of right ventricular function during right ventricular bypass
}

\author{
B SETHIA, IJ REECE, A TWEDDEL, W MARTIN, KM TAYLOR \\ From the Departments of Cardiac Surgery and Cardiology, Royal Infirmary, Glasgow
}

Use of a left ventricular assist device to support patients with cardiogenic shock refractory to medical treatment and intra-aortic balloon pumping is well established..$^{-3}$ The use of such techniques is particularly valuable after coronary revascularisation procedures. Although the clinical and haemodynamic consequences of right ventricular infarction are well documented, ${ }^{4}$ acute isolated right ventricular damage with haemodynamically important dysfunction is rare after coronary revascularisation.

Pulmonary artery balloon counterpulsation has been successfully used to support the right ventricle in the presence of moderate right ventricular dysfunction. ${ }^{5}$ A suitable external or internal pump must be used, however, when severe dysfunction occurs. ${ }^{6}$

This paper reports a case in which postoperative cardiogenic shock secondary to acute, isolated right ventricular dysfunction was treated by extracorporeal right ventricular bypass. Assessment of right ventricular function, performed with serial technetium scans, showed improvement in function before termination of ventricular assistance.

\section{Case report}

A 54 year old man was admitted for elective coronary artery surgery. Investigations had shown a critical stenosis in his left main coronary artery and a $40 \%$ stenosis near the ostium of the right coronary artery. There were tight proximal lesions in the left anterior descending and main circumflex vessels.

At operation the left anterior descending, first diagonal, and obtuse marginal branch of the circumflex coronary arteries were grafted with lengths of reversed saphenous vein. Measured graft flows were 40,50 , and $70 \mathrm{ml}$ per minute respectively. The right coronary artery was exposed and opened. The lumen could not be found and it was impossible to perform endarterectomy. The posterior descending artery was less than $1 \mathrm{~mm}$ in diameter and was not considered for grafting. When cardiopulmonary bypass was discontinued the inferior surface and the lower part of the anterior wall of the right ventricle were seen to be akinetic and gross right ventricular distension occurred. After a further period of supportive bypass it was possible to discontinue bypass; the patient returned to the intensive care unit in a stable condition with a blood pressure of $120 / 80 \mathrm{~mm} \mathrm{Hg}$ and a central venous pressure of $15 \mathrm{~mm}$ $\mathrm{Hg}$.

Address for reprint requests: Mr B Sethia FRCS, Department of Cardiothoracic Surgery, Royal Infirmary, Glasgow G31 2ER.

Accepted 12 April 1985
Twelve hours after operation the patient became hypotensive (blood pressure $65 / 40 \mathrm{~mm} \mathrm{Hg}$ ) and the chest was reopened. The right ventricle was noted to be infarcted and akinetic except at the infundibulum. The left atrial pressure was $2 \mathrm{~mm} \mathrm{Hg}$ and the right atrial pressure $27 \mathrm{~mm}$ Hg. All grafts were seen to be patent. Treatment with dopamine and volume loading produced some improvement and the chest was closed. Cardiogenic shock persisted, however, and the chest was reopened three hours later. Right ventricular bypass was instituted with a $10 \mathrm{~mm}$

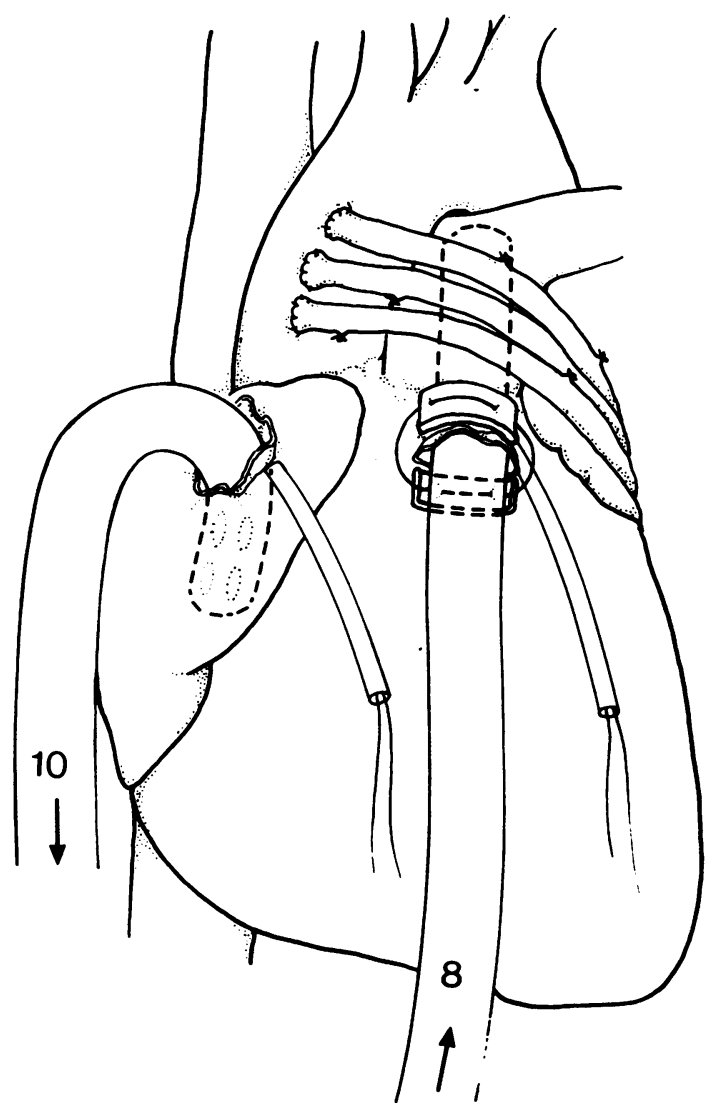

Fig 1 Cannulation sites for right ventricular bypass. Note the problem of siting the pump outflow cannula in the presence of aortocoronary grafts. $10=10 \mathrm{~mm}$ Rygg cannula; $8=8 \mathrm{~mm}$ venous cannula. 


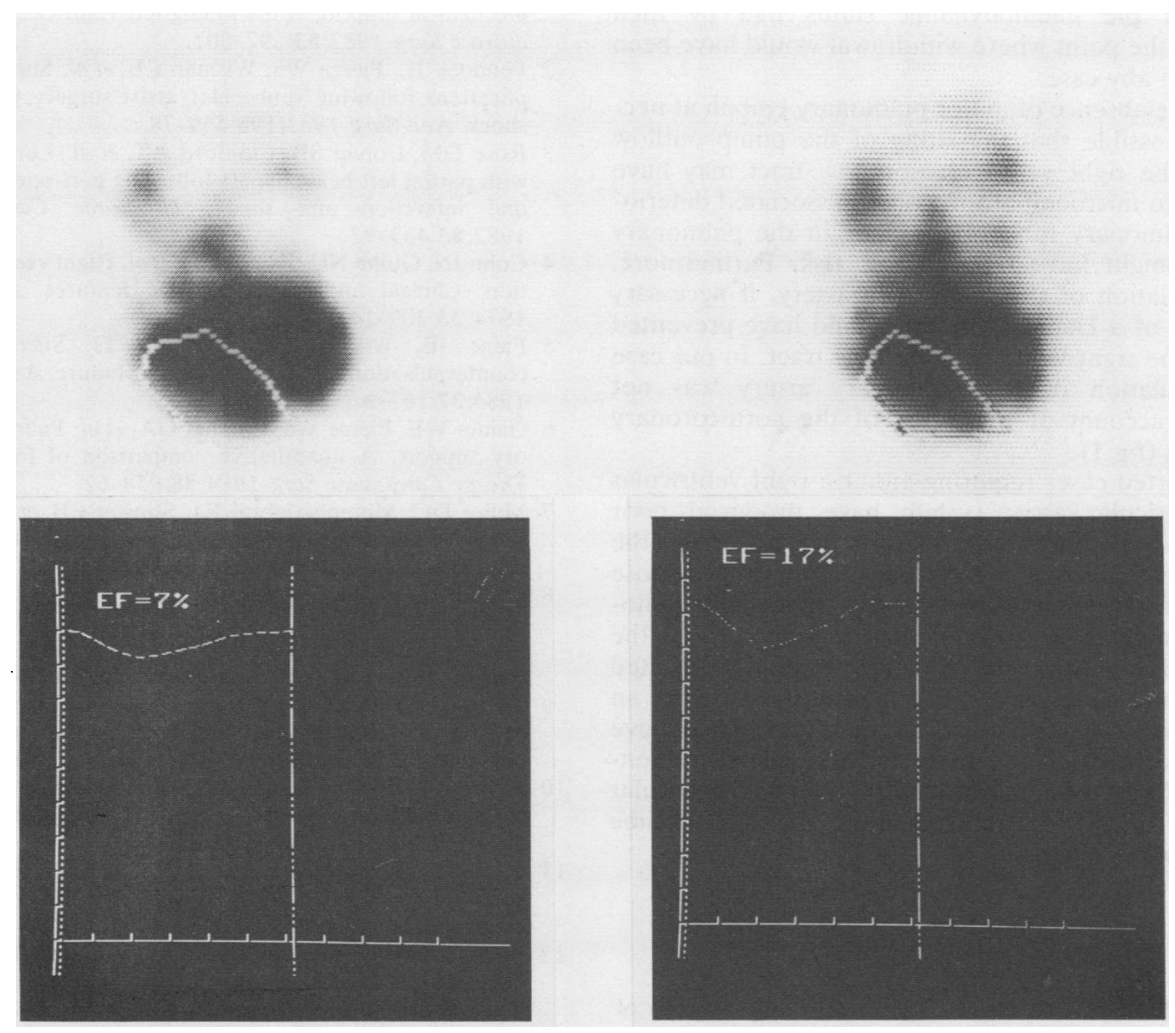

Fig 2 Serial gated technetium $99 \mathrm{~m}$ radioisotope studies (left) after the start of right ventricular bypass and (right) after 20 hours of right ventricular bypass, showing an improvement in right ventricular function that is most pronounced at the apex.

angled Rygg cannula in the right atrium inserted via the appendage for venous return and an $8 \mathrm{~mm}$ venous cannula inserted into the pulmonary artery from the right ventricular outflow tract (fig 1). A Stockert roller pump with a non-pulsatile flow of $4.5 \mathrm{~V} / \mathrm{min}$ provided right ventricular decompression. The chest was packed and left open. Direct measurement of right ventricular and left atrial pressure was used to ensure complete right ventricular decompression and adequate left ventricular preload.

The patient was given anticoagulant treatment with 300 units per $\mathrm{kg}$ of heparin. Over the next 20 hours his clinical condition rapidly improved and serial technetium scans (fig 2) showed clear evidence of improvement in right ventricular function. Over this period, however, pulmonary function (reflected by serial estimations of arterial blood gases) deteriorated, possibly as a result of microemboli from the roller pump circuit. Bypass was therefore discontinued after 22 hours.

Over the next 30 hours the patient deteriorated with progressive increase in right atrial and right ventricular pressures and associated evidence of systemic hypoperfusion. Despite increased inotropic support he died 70 hours after surgery. At necropsy the three aortocoronary grafts were found to be patent. There was massive right ventricu- lar infarction and the lungs were congested, although there was no evidence of major pulmonary emboli.

\section{Discussion}

It is now well recognised that right ventricular dysfunction may occasionally occur after coronary revascularisation, and in rare cases may be the primary cause of death. ${ }^{7}$ In most cases, however, there is evidence of associated left ventricular dysfunction and right ventricular infarction rarely presents as an isolated entity after coronary artery surgery.

In our patient perioperative myocardial infarction and right ventricular distension were responsible for the acute right ventricular failure, which persisted despite volume loading and use of inotropic agents. Although pulmonary artery balloon counterpulsation may be useful in these circumstances, ${ }^{11}$ both experimental ${ }^{6}$ and clinical studies ${ }^{12}$ suggest that right ventricular bypass is the most appropriate treatment when right ventricular function is severely compromised. This view is supported by the observation of a definite improvement in our patient's right ventricular function over the subsequent 24 hours. Deteriorating pulmonary function eventually precipitated withdrawal of 
support, but the haemodynamic status had by then improved to the point where withdrawal would have been considered in any case.

Despite the absence of major pulmonary emboli at necropsy it is possible that the siting of the pump outflow cannula in the right ventricular outflow tract may have contributed to microembolism with an associated deterioration in pulmonary function. A filter in the pulmonary artery line might have reduced this risk. Furthermore, direct cannulation of the pulmonary artery, if necessary with the use of a Dacron conduit, would have prevented damage to the right ventricular outflow tract. In our case direct cannulation of the pulmonary artery was not possible on account of the siting of the aortocoronary bypass grafts (fig 1 ).

Most reported cases requiring either a right ventricular or a biventricular assist system have produced poor results ${ }^{10}$ and obviously more work is needed before the results of right ventricular assistance can approach those of left ventricular assistance. Our experience with radionuclide scanning agrees with a recent report ${ }^{8}$ in which the improvement in right ventricular function was documented two weeks and six months after operation following an episode of acute right ventricular failure. We also believe that serial technetium scanning during mechanical ventricular assistance may provide a useful index of ventricular function and be of value in determining the optimal time for discontinuing bypass.

\section{References}

1 Golding LR, Jacobs G, Groves LK, et al. Clinical results of

\section{Book notice}

A colour atlas of cardiac surgery: congenital heart disease. Vol 2. James L Monro and Gerald Shore. (Pp 192; £55.) Wolfe Medical Publications, 1984.

Together with the previously published Coloured Atlas on Surgery for Acquired Heart Disease, this volume is part of a series of medical and surgical atlases. Each of its 19 chapters is introduced by a brief explanatory text and simple but lucid line drawings before proceeding to describe the operative procedures for the more common congenital abnormalities. This is done by a sequence of coloured photographs, the outstanding quality of which is maintained throughout the book. Although diagrams or line drawings may not accurately portray how things appear, mechanical support of the failing left ventricle. $J$ Thorac Cardiovasc Surg 1982;83:597-601.

2 Pennock JL, Pierce WS, Wisman CB, et al. Survival and complications following ventricular assist surgery for cardiogenic shock. Ann Surg 1983;198:469-78.

3 Rose DM, Colvin SB, Culliford AT, et al. Longterm survival with partial left heart bypass following peri-operative myocardial infarction and shock. J Thorac Cardiovasc Surg 1982;83:483-92.

4 Cohn JN, Guiha NH, Broder MI, et al. Right ventricular infarction. Clinical and haemodynamic features. Am J Cardiol 1974;33:209-14.

5 Flege JB, Wright CB, Reisinger TJ. Successful balloon counterpulsation for right ventricular failure. Ann Thorac Surg 1984;37: 167-8

6 Gaines WE, Pierce WS, Prophet GA, et al. Pulmonary circulatory support. A quantitative comparison of four methods. J Thorac Cardiovasc Surg 1984;88:958-62.

7 Miller DC, Moreno-Cabral RJ, Stinson EB, et al. Pulmonary artery balloon counterpulsation for acute right ventricular failure. J Thorac Cardiovasc Surg 1980;80:760-3.

8 O'Neill MJ, Pierce WS, Wisman CB, et al. Successful management of right ventricular failure with the ventricular assist pump following aortic valve replacement and coronary bypass grafting. J Thorac Cardiovasc Surg 1984;87:106-11.

9 Taguchi K, Hasegawa T, Fukunaga S, et al. Safe conduct of flow assist with prolonged ventricular bypass and experience with 34 patients. Trans Am Soc Artif Intern Organs 1982;28:100-3.

10 Pierce WS, Parr GVS, Myers JL, et al. Ventricular assist pumping in patients with cardiogenic shock after cardiac operations. N Engl J Med 1981;305:1606-10.

11 Moran JM, Opravil M, Gorman AJ, et al. Pulmonary artery balloon counterpulsation for right ventricular failure: II. Clinical experience. Ann Thorac Surg 1984;38:254-9.

12 Pennington DG, Merjavy JP, Swartz MT, et al. The importance of biventricular failure in patients with postoperative cardiogenic shock. Ann Thorac Surg 1985;39:16-26. they may still communicate a principle more effectively than can be done by a photograph. So while the book describes the surgical method with remarkable clarity, some of the underlying concepts do not always come over with equal force. In this sense it may not be completely comprehensive; nevertheless, this volume does make a unique and innovative contribution to a full understanding of the surgical procedures. For whom is this book written? The authors have "aimed at junior doctors starting cardiac surgery" but actually hope that it will be read by all and sundry. Few individuals who are not committed to cardiology are likely to invest in such an expensive book, but it should certainly stand alongside other texts of cardiac surgery on the shelves of the cardiology and cardiac surgical libraries.-JDW 